Western University Scholarship@Western

Centre for the Study of International Economic

Relations Working Papers

Centre for the Study of International Economic

Relations

1984

\title{
Best Approximate Aggregation of Input-Output Systems
}

Glenn W. Harrison

Richard Manning

Follow this and additional works at: https://ir.lib.uwo.ca/economicscsier_wp

Part of the Economics Commons

Citation of this paper:

Harrison, Glenn W., Richard Manning. "Best Approximate Aggregation of Input-Output Systems." Centre for the Study of International Economic Relations Working Papers, 8401C. London, ON: Department of Economics, University of Western Ontario (1984). 
CENTRE FOR THE STUDY OF INTERNATIONAL ECONOMIC RELATIONS

WORKING PAPER NO. 8401C

BEST APPROXIMATE AGGREGATION OF INPUT-OUTPUT SYSTEMS

\author{
Glenn W. Harrison \\ Richard Manning
}

\title{
JAN - 91984
}

This paper contains preliminary findings from research work still in progress and should not be quoted without prior approval of the authors.

DEPARTMENT OF ECONOMICS UNIVERSITY OF WESTERN ONTARIO LONDON, CANADA N6A $5 \mathrm{C} 2$
Department of Ecosonics Library

FEB $\{41992$

University of Wespam Ontatio 
BEST APPROXIMATE AGGREGATION OF INPUT-OUTPUT SYSTEMS ${ }^{1}$

by Glenn W. Harrison and Richard Manning

A method of constructing aggregate input-output systems is proposed. The procedure minimizes the meansquare error of aggregate predictions. If consistent aggregation is possible it gives the solution to the problem. The range of data on which the aggregate model is to be applied influences the best approximate aggregate. In a special case, W. D. Fisher's aggregated model emerges. Best approximate aggregates maximize Ijiri's coefficient of aggregation. Computations reveal that best approximate aggregation is feasible, and in realistic cases yields considerably better predictions than alternative methods.

\section{INTRODUCTION}

Input-output systems are the basis of most applied general equilibrium analysis. Since these systems are typically of large dimension, it is often convenient to reduce them in size by aggregating groups of industries. There is usually a natural method of aggregation based on product or process similarities. When the aggregate industries are identified, an aggregate input-output matrix is needed to analyze their behavior. Unfortunately the classic results on consistent aggregation offer little help in providing the aggregate input-output matrix. This is because these results require aggregation to be exact. In general, aggregation involves an error。 If a loss function is defined on this aggregation error then the aggregate 
input-output matrix can be selected by minimizing the loss function. This paper develops best approximate aggregate input-output matrices in this way. The properties of these matrices are described and their superiority over aggregate input-output matrices constructed in other ways is demonstrated for real systems.

This approach to aggregation has been made before. Walter D. Fisher applied a loss-minimizing principle to problems of aggregation of input-output systems. His work displayed great insight, but has been neglected by practitioners of input-output analysis who continue to use aggregation methods not based on theoretical principles. It is not appropriate to speculate here on the reasons for this neglect. Rather, a simplified account of this method of aggregation is given. Unlike Fisher, and others who worked on the assumption of consistent aggregation, the primary emphasis here is on the selection of the aggregate system, not on the choice of industries to aggregate.

The next section begins by reviewing the theory of consistent aggregation, which motivates the development of best approximate aggregation. Some properties of best approximate aggregate input-output systems, and of predictions based on them, are also given there. In the third section related work on aggregation is briefly reviewed. Also established there are the connections with earlier work on aggregation in input-output. Section 4 reports the results of applying best approximate aggregation to large-scale, real examples. Input-output tables for the U.S.A., Australia, and a multicountry table for the Pacific Basin, are each aggregated. The aggregate systems are shown to be markedly superior to those generated by standard 
methods (including an official aggregated input-output table for Australia). Implications of these results for general equilibrium modelling, along with other applications of the method, are discussed in the final section of the paper.

\section{MEAN-SQUARE ERROR MINIMIZING AGGREGATION}

The classic results concerning the consistent aggregation of inputoutput systems are first presented. This allows the introduction of some important concepts.

An input-output matrix A (A non-negative) relates the gross output of commodities, denoted by a vector $x$, to the amounts of those commodities used up within the economy, Ax. Suppose that $A$ is $n \times n$, and that $x$ is $n \times 1$. The net output is a vector $y$, also $n \times 1$, which is given by

$$
\text { (2.1) } \quad y=\left[I_{n}-A\right]_{x}
$$

where $I_{n}$ is the $n \times n$ identity matrix.

It is convenient to call $x$ the exogenous variable, $y$ the endogenous variable, and $\left[I_{n}-A\right]$ the model. Although a particular interpretation is placed on these terms in the theoretical development, other interpretations are possible, and some will be made in the later application of the technique. Two alternative interpretations made are:

(i) The exogenous variable is net output (or final demand), so that the endogenous variable is gross output, and the model is the inverse of the net input-output matrix (the "Leontief Inverse"); and

(ii) The exogenous variable is primary input cost, so that the endogenous variable gives commodity prices, and the model is the inverse of the transposed net input-output matrix (the "Leontief Inverse transpose"). 
The exogenous and endogenous variables $x$ and $y$ may be reduced in dimension by an aggregator $T$, where $T$ is a non-negative $m \times n$ matrix, $\mathrm{m}<\mathrm{n}$, rank $\mathrm{T}=\mathrm{m}_{0}$. This gives an aggregated exogenous variable $\mathrm{X}$, and an aggregated endogenous variable $Y$, both $m \times 1$, where

(2.2) $\quad X=T x, Y=T y$.

$T$ is assumed to be given. The extent of aggregation is determined by $m$. The industries that are to be aggregated determine the structure of $T$ (the full rank assumption guarantees that aggregated industries are different). There is invariably some clear and intuitive criterion for the aggregation scheme chosen. For example, a disaggregated input-output system contains many agricultural and many manufacturing-industry sectors (among others): A natural aggregator would group together the inputs to (and outputs from) all agricultural sectors, and group together all manufacturing-industry sectors as a separate aggregate industry (specific instances of this are given in Section 4).

Economic analysis of the aggregate variables requires a relationship between $X$ and $Y_{0}$. This suggests the usual approach to aggregation, which is based on the following definition (see Richmond [32; p. 48] for a general statement of this sort).

DEFINITION 2.1 The mode1 $\left[I_{n}-A\right]$ relating the exogenous variable $x$ to the endogenous variable $\mathrm{y}$, can be consistently aggregated by the aggregator $T$ if and only if there exists an aggregated model $\left[I_{m}-B\right]$ such that (2.3) $\quad \mathrm{Y}=\left[I_{\mathrm{m}}-B\right] \mathrm{X}$, where $\mathrm{X}=\mathrm{Tx}$, for all $\mathrm{x} \in \mathrm{R}^{\mathrm{n}}$. 
Of course $B$ is $m \times m$, and $I_{m}$ is the $m \times m$ identity matrix. Notice that the exogenous variables are not at all restricted in this definition. PROPOSITION 2.1 The modeI [ $\left.I_{n}-A\right]$ can be consistent ly aggregated by the aggregator $T$ if and only if the matrix equation $(2.4) \quad \mathrm{BT}=\mathrm{TA}$

has a solution $B$. This solution gives the aggregated model.

PROOF: Substituting for $y$ in (2.2) from (2.1) gives

(2.5) $\quad \mathrm{Y}=\mathrm{T}\left[\mathrm{I}_{\mathrm{n}}-\mathrm{A}\right]_{\mathbf{X}}$

Substituting for $X$ in (2.3) from (2.2) gives

(2.6) $\quad Y^{*}=\left[I_{m}-B\right] T_{x}$

But Definition 2.1 requires $\mathrm{Y}=\mathrm{Y}^{*}$ for a11 $\mathrm{X}$. Therefore

(2.7) $\quad T\left[I_{n}-A\right]=\left[I_{m}-B\right] T$

Since (2.4) is equivalent to $\mathrm{mn}$ linear equations in $\mathrm{m}^{2}$ unknowns (the elements of $B$ ), and $\mathrm{m}^{2}<\mathrm{mn}$, no aggregated model exists in general。 Although some rank conditions on $A$ and $T$ will ensure that $B$ exists, there is no reason to expect that these conditions will be satisfied for an arbitrary model and aggregator. An alternative approach is needed. Before providing this, note that post-multiplying both sides of $(2.4)$ by $\mathrm{T}^{\prime}$, and then by $\left(\mathrm{TT}^{\prime}\right)^{-1}$ gives

$(2.8) \quad \mathrm{B}=\left(\mathrm{TAT}^{\prime}\right)\left(\mathrm{TT}^{\prime}\right)^{-1}$

if it exists. This will be used later. 
The restricted usefulness of consistent aggregation clearly stems from Definition 2.1 which requires that $\mathrm{Y}=\mathrm{Y}^{*}$, where these are calculated as in $(2.5)$ and $(2.6)$ respectively. For a given exogenous variable $x$, (2.5) gives the true value of the aggregate endogenous variable $Y$. For the same value of $x$, and for an arbitrary aggregate model $\left[I_{m}-B\right],(2.6)$ may be regarded as giving a prediction of $Y$. There is no reason to suppose (but consistent aggregation does so) that the prediction coincides with the true value of the aggregated endogenous variable. That is

$$
(Y *-Y \mid x)=\left(\left[I_{m}-B\right] T-T\left[I_{n}-A\right]\right) x \neq 0
$$

in general. This is the aggregation error ${ }^{2}$ (conditional on the exogenous variable). While the model and the aggregator are given, the aggregate model can be chosen. The aggregation errors depend on this choice. Although the exogenous variable can range over $R^{n}$, some values are more likely to be met than others. It is assumed that the user of the aggregated model has a subjective probability density function $g(x)$ which gives the relative frequency with which the exogenous variable takes the value $x$. Call $g$ the use density of the aggregated model. Since good predictions should be available when they are needed, the use density must be taken into account. For instance, if the aggregated model is to be used in an IDC it would be inappropriate to have it fit better to the output' structure found in an advanced, rich, economy. The use density in this case would place most weight on output levels and structures near those likely to be found in the IDC. 
With the use density known, the mean-square error can be calculated from

$$
\begin{aligned}
M(B \mid A, T, g) & =E_{g}\left[\left(Y^{*}-Y\right)^{\prime}\left(Y^{*}-Y\right)\right] \\
& =E_{g}\left[x^{\prime}\left(\left[I_{m}-B\right] T-T\left[I_{n}-A\right]\right)^{\prime}\left(\left[I_{m}-B\right] T-T\left[I_{n}-A\right]\right) x\right]
\end{aligned}
$$

where $E_{g}$ denotes expectation over $x$ with distribution $g$.

DEFINITION 2.2 The best approximate aggregate model $\left[I_{m}-B^{*}\right]$, given the model $\left[I_{n}-A\right]$, the aggregator $T$, and the use density $g$, is given by that $B^{*}$ which minimizes $M(B \mid A, T, g)$.

It is obvious that if consistent aggregation is possible then the resulting model is also the best approximate aggregate model (since $M(B \mid A, T, g)$ cannot be less than zero, which is its value when $Y=Y^{*}$ as required for consistent aggregation). Thus, best approximate aggregation generalizes the classical concept of consistent aggregation.

PROPOSITION 2.2 Given the model $\left[I_{n}-A\right]$, the aggregator $T$, and the use density $g$, the best approximate aggregate model is given by

$$
\text { (2.11) } \quad B^{*}=E_{g}\left[T A x x^{\prime} T^{\prime}\right]\left[E_{g}\left[T_{x x^{\prime}} T^{\prime}\right]\right]^{-1}
$$

if it exists and is finite.

PROOF: It is necessary for an interior minimum that $B^{*}$ satisfies

$$
\text { (2.12) } \quad \frac{\partial M(B \mid A, T, g)}{\partial B}=0
$$

Now

$$
\text { (2.13) } \quad \frac{\partial M(B \mid A, T, g)}{\partial B}=E_{g}\left[\frac{\partial Q(B \mid A, T, g)}{\partial B}\right]
$$

where 
$(2.14)$

$$
Q(B \mid A, T, g)=x^{\prime}\left(\left[I_{m}-B\right] T-T\left[I_{n}-A\right]\right)^{\prime}\left(\left[I_{m}-B\right] T-T\left[I_{n}-A\right]\right) x \text {. }
$$

It can be shown ${ }^{3}$ that

(2.15) $\quad \frac{\partial Q(B \mid A, T, g)}{\partial B}=2\left(B T x_{x}^{\prime} T^{\prime}-T A x x^{\prime} T^{\prime}\right)$.

Substituting (2.15) into (2.13) and applying (2.12) gives (2.11).

It has already been noted that best approximate aggregation generalizes consistent aggregation. This can also be seen by comparing (2.8) and (2.11): Their form is similar. Indeed, if consistent aggregation is possible (2.4) may be used to substitute for TA in the first expectation in $(2.11)$. But then

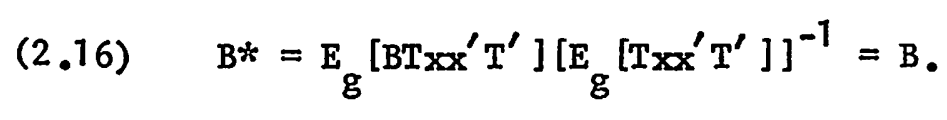

Thus, if consistent aggregation is possible then (2.11) gives the corresponding aggregated model.

Several desirable features are displayed by $B^{*}$, which can be expressed as a functional $B *(A, T, g)$ to indicate its dependence on the model, aggregator and use density.

PROPOSITION 2.3 The best approximate aggregate model is given by $\mathrm{B} *(A, \mathrm{~T}, \mathrm{~g})$ which

(i) is homogeneous of degree zero in $\mathrm{T}$;

(ii) for $g_{1}, g_{2}$ such that $g_{1}(x)=g_{2}(\lambda x), \forall x, \lambda>0$ constant, is such that

$$
B^{*}\left(A, T, g_{1}\right)=B^{*}\left(A, T, g_{2}\right)
$$

(iii) may be written as 
(2.17) $\quad B *=\left[T A\left(\Omega_{g}+\mu_{g} \cdot \mu_{g}^{\prime}\right) T^{\prime}\right]\left[T\left(\Omega_{g}+\mu_{g} \cdot \mu_{g}^{\prime}\right) T^{\prime}\right]^{-1}$

where $\Omega_{g}$ is the covariance matrix of $x$, when $g$ is its distribution, and $\mu_{g}$ is its mean.

(iv) depends only on the first two moments of $x$.

PROOF: (i) It is obvious from $(2.11)$ that $B *$ is unaffected if $T$ is multiplied by a scalar.

(ii) Changing $x$ to $\lambda x$ in $(2.11)$ leaves $B^{*}$ unaffected.

(iii) $B^{*}$ in $(2.11)$ may be written as

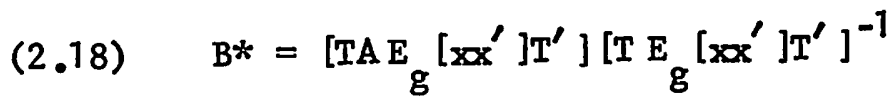

This may be simplified to $(2.17)$ by substituting the well-known identity (2.19) $\quad \mathrm{E}_{\mathrm{g}}\left[\mathrm{xx}^{\prime}\right]=\Omega_{\mathrm{g}}+\mu_{\mathrm{g}} \cdot \mu_{\mathrm{g}}^{\prime}$ (iv) is obvious from $(2.17)$.

Results (i), (ii) and (iv) of this Proposition give situations in which the best approximate aggregate is insensitive to changes. Consideration of the sensitivity of the aggregate model to the method of aggregation, the model, and the use density, are best performed numerically. Note that (i) says that identical changes in the units of measurement of all the aggregated variables leaves the best approximate aggregate model unchanged. It does not say that a change in measurement of one aggregate variable has this property. Indeed, such a change is equivalent to giving a different weight to the squared prediction error of that aggregate sector. One straightforward extension of the method given here is to assign weights to the prediction errors of the sectors in a way that reflects the relative 
seriousness of these errors. (This extension is left to the reader.) Stated in (ii) is the invariance with respect to changes in the scale of the economy of the best approximate aggregate input-output matrix. That is, merely expanding the size of the economy, without altering its output structure, will not affect the best aggregate representation of the economy.

The formula (2.17) is used in Section 4. It relies (as does (iv)) on the use of the mean-squared error loss function. Alternative Ioss functions might be appropriate (where the errors of over-prediction differ from those of under-prediction an asymmetric loss function would be better, for instance. This extension is also left to the reader).

Proposition 2.1 assumes that there is a best approximate aggregate, that it is finite, and that (2.11) minimizes $(2.10)$. These assumptions are justified if the use density has finite second-order moments. That is, if

(2.20) $\quad E_{g}\left[x^{\prime} x^{\prime}\right]$ is finite then $M(B \mid A, T, g)$ defined in $(2.10)$ is finite, so it can be minimized and $B *$ specified in $(2.11)$ is finite, while

(2 .21) $\quad \frac{\partial^{2} M(B \mid A, T, g)}{\partial \mathrm{B}^{2}}=2 \mathrm{TE}\left[\mathrm{xx}^{\prime}\right] \mathrm{T}^{\prime}$

is positive semi-definite so that $B *$ is indeed a minimu. Of course $(2.20)$ is no limitation for practical purposes.

A major reason for aggregation is that it is simpler to make aggregate predictions using an aggregate model than it is to operate with a detailed, 
disaggregated system. Such aggregate predictions involve an intrinsic, essentially random, error however. Using the best approximate aggregate matrix $B^{*}$, the aggregate prediction error conditional on a value of the aggregate exogenous variable is given by

$(2.22) \quad\left(Y^{*}-\mathrm{Y} \mid \mathrm{X}\right)=\left[I_{\mathrm{m}}-B^{*}\right] \mathrm{X}-(\mathrm{Y} \mid \mathrm{X})$.

Now the term $\left[I_{m}-B^{*}\right] X$ is determinate, but the term $(Y \mid X)$ is not. This is because many values of the exogenous variable aggregate to the given value of the aggregate exogenous variable. Formally,

(2.23) $\quad(\mathrm{Y} \mid \mathrm{X}) \in\left\{\mathrm{Y} \mid \mathrm{Y}=\mathrm{T}\left[\mathrm{I}_{\mathrm{n}}-\mathrm{A}\right]_{\mathrm{X}}, \quad \mathrm{XX}_{\mathrm{X}} \in \mathrm{V}(\mathrm{X})\right\} \equiv \mathrm{Z}(\mathrm{X})$

where $V(X)=\left\{x \in R^{n} \mid T x=X\right\}$. That is, conditional on a value of the aggregate exogenous variable, the actual value of the aggregate endogenous variable belongs to the set $\mathrm{Z}(\mathrm{X})$ (which is defined, in part, by possible values of the exogenous variable). Therefore the aggregate prediction error in (2.22) is multi-valued.

Suppose now that a probability density function $f_{X}$ is defined over $V(X)$. This gives the (subjective) probability that the exogenous variable takes on a particular value consistent with the value of the aggregate exogenous variable. It may be that $f_{X}$ is derived from the use density $g$, but in some situations it will be quite different. This is so, in particular, if there is available to the analyst some detailed knowledge about the economic structure that is not included in $g$. In any event, $f_{X}$ induces a distribution over $\mathrm{Z}(\mathrm{X})$ : Then $(\mathrm{Y} \mid \mathrm{X})$ is a random variable, as is the prediction error in 
(2.22). The expectation and covariance of these prediction errors are easily calculated.

PROPOSITION 2.4 The conditional aggregate prediction error is a random variable with mean

$$
E[Y *-Y \mid X]=\left[I_{m}-B *\right] X-T\left[I_{n}-A\right] E_{f}[x]
$$

and covariance

$$
\operatorname{Cov}[Y *-Y \mid X]=T\left[I_{n}-A\right] \operatorname{Cov}_{f}[X]
$$

where $E_{f}[x]$ and $\operatorname{Cov}_{f}[x]$ are the mean and covariance of $x$ respectively.

Several features of this result deserve comment. First, the random prediction error arises even though the model and aggregation procedures are deterministic. The explanation of this is intuitive. Information is lost when aggregation occurs. This loss of information shows up as an inability to make precise predictions. Secondly, the expected prediction error is not zero. In other words, the best approximate aggregate model generally gives "biased" predictions. This could only be avoided by imposing unwarranted restrictions on $f_{X}$. Thirdly, the covariance of the aggregate prediction error may be applied to Chebychev's inequality to make statements about the accuracy of predictions.

Finally, it is natural to define

(2.26) $\quad R^{2}=1-\frac{E_{g}\left[\left(Y^{*}-Y\right)^{\prime}\left(Y^{*}-Y\right)\right]}{E_{g}\left[(Y-\bar{Y})^{\prime}(Y-\bar{Y})\right]}$

where $\bar{Y}=E_{g}\left[T\left[I_{n}-A\right] X\right]$, as a measure of the success of aggregation (see Ijiri [16, p. 256, eq. (20)] for this measure). This is the proportion of 
the variation of the aggregate endogenous variable about its mean that is "explained" by the (best approximate) aggregate model. The measure, of course, applies to any aggregate model. Note that the best approximate aggregate model maximizes $R^{2}$, and that $R^{2}=1$ if and only if consistent aggregation is possible.

\section{COMPARISONS WITH THE IITERATURE}

The form of the equation for $\mathrm{B}^{*}$ (in $(2.11)$ ), the uncertainty associated with predictions (Proposition 2.4), and the measure of goodness of aggregation $\left(\mathrm{R}^{2}\right.$ in $\left.(2.26)\right)$ are similar to those found in econometric estimation theory. This suggests an underlying unity between the aggregation problem and econometric estimation. This has been long recognized. In surveying the state of aggregation theory, Allen [1, p. 694] wrote:

\footnotetext{
"The model is then based on economic theory in the form of many micro-relations between micro-variables, but expressed in terms of an economic-statistical construction of macrorelations between aggregate variables."
}

The general necessity of this "economic-statistical construction" can be usefully illustrated by the present case. Given the use density $g$ on $x$, a multi-variate distribution is induced on $(\mathrm{X}, \mathrm{Y})\left(=\left(\mathrm{T}_{\mathrm{x}}, \mathrm{T}\left[\mathrm{I}_{\mathrm{n}}-\mathrm{A}\right]_{\mathrm{X}}\right)\right)$. Provided that this induced distribution is non-degenerate, the relationship of $Y$ to $X$ is necessarily statistical, so that predictions based on any deterministic relationship of these aggregates will be subject to error. The multivariate distribution on $(X, Y)$ implies the econometric-like, decision-theoretic, approach suggested in this paper. Such an approach is in contrast to that dominating the literature on aggregation. 
The possibility, in one form or another, of consistent aggregation has been the focus of most aggregation theory, in general, and in the inputoutput application in particular. May [24;25] appeared to fix the model and method of aggregation, as is done here in Definition 2.1 , and ran into the problem Proposition 2.1 makes plain: There is usually no consistent (or exact) aggregate model. In the case of input-output, this conclusion is found in Fei [8] and Hatanaka [15]。An apparently more useful approach was suggested by KIein [19] and by Leontief in a celebrated paper [20]. The requirement of consistent aggregation is maintained, but the method of aggregation is the subject of choice. For input-output, this becomes a question of whether or not there are both $B$ and $T$ satisfying (2.4). Conditions on $A$ ensuring this are given by Ara [2], McManus [22; 23], and Morimoto [27; 28]. Not surprisingly, consistent aggregation is more likely to be arranged when the aggregator can be chosen than when it cannot. However, it does not seem to be helpful to know that there is some way of aggregating industries which will yield exact predictions (and it is not possible in general anyway). Apart from the strange groupings that might be needed to achieve this, there is a more fundamental objection: The method of aggregation will depend on the model. As a consequence, aggregate comparisons could never be made between countries with different technologies. Most aggregate industries found in practice will be obvious groupings.

Several writers have endeavoured to replace consistent aggregation. Errors must then be expected: Aggregation can only be approximate. F. M. Fisher [9] developed one sort of result concerning this for general systems. His interest was whether there were aggregators which gave nearly 
correct answers if Leontief's separability requirement was satisfied approximately. That is, he was concerned with finding an aggregator which worked reasonably well. It is natural to make this precise by specifying the costs of making errors. ${ }^{4}$ For input-output, this was the (earlier) intuition of Walter D. Fisher [10], who sought that aggregator which minimized mean-square prediction error. According to Neudecker [29, p. 922] Fisher proposed ${ }^{5}$ that the aggregate model be (in the notation of this paper) (3.1) $\quad \hat{B}=\left[T A\left(x_{0}\right) T^{\prime}\right]\left[T\left(x_{0}\right) T^{\prime}\right]^{-1}$

where $\left(x_{0}\right)$ is the diagonal matrix made up from the vector of base-level gross outputs. The following is obvious.

PROPOSITION 3.1 If $\Omega_{g}=\left(x_{0}\right), \mu_{g}=0$, then $\hat{B}=B^{*}$.

That is, if the variance of the use density equals the base-level gross output, and the expected level of the gross output is zero, then Fisher's aggregate model coincides with the best approximate aggregate model. Therefore, best approximate aggregation generalizes Fisher's method (although, it must be stressed, he was principally interested in the method of aggregation, not in the aggregate mode1).

Information theory provides an alternative choice-theoretic method of aggregation. Theil [39] and Theil and Uribe [40] have developed this. Although some use has been made of the method, its emphasis is also on finding the best aggregator (see Roy, Batten and Lesse [34]). Moreover, the criterion of information-loss has relatively little economic appeal. The prediction errors due to aggregation will be compounded if the model itself is subject to error. Recently, West $[41 ; 42 ; 43]$, following 
the earlier work of Quandt [30; 31] and Gerking [12], has given results on the distribution of prediction errors from this source.

Finally, it must also be noted that there is an extensive literature on aggregation in econometrics. Chipman [5] provides a collection of results formally close to those given here (and he uses the term "best approximate aggregate" to describe the aggregate model). However, the present problem is about aggregating theoretical relationships, while Chipman explains how observed data should be aggregated.

\section{APPLICATIONS}

A number of illustrative applications of the Best Approximate Aggregation (BAA) method are now presented, along with comparisons with the results of Naive Aggregation .

Three matrices are considered: the Direct Requirements matrix (I-A); the Leontief Inverse $(I-A)^{-1}$; and the Leontief Inverse Transpose $\left(I-A^{\prime}\right)^{-1}$. The applications of the first two matrices for interindustry forecasting and impact analysis are well known. The third matrix is widely used in the effective tariff protection literature (cf. Corden [6]), in the tax incidence literature (cf. Melvin [26]), and in the numerical general equilibrium policy literature (cf. Harrison and Kimbe11 [13], Kimbe11 and Harrịson [18], Scarf and Shoven [35], and Shoven and Whalley [36])。

In each of the applications it is assumed that the distribution over the $\mathbf{x}$ vector is either Multinomial or Multivariate Normal (cf. De Groot [7; pp. 48-9, 51-6]). Each distribution has advantages and disadvantages for .

present purposes. The Multinomial is parsimonious with respect to calibration, 
but does not allow independent first and second moments; the Multivariate Normal requires the specification of a large number of covariance terms about which there is relatively little intuition, but allows independent calibration of the first two moments. At this stage there is no reason to be dogmatic about the form of the use density. These two are for illustrative purposes only.

The Multinomial distribution is calibrated and interpreted as follows. Let $\mathrm{N}$ denote the number of observations in the sample, $p_{i}$ denote the probability that the outcome belongs to the $i^{\text {th }}$ category $(i=1,2, \ldots, n)$, and $x_{i}$ denote the number of these outcomes belonging to category $i$. Then $\mu_{i}=N p_{i}$, all $i$, and

$$
\Omega_{i j}= \begin{cases}N p_{i}\left(1-p_{i}\right) & i=j(i, j=1, \ldots, n) \\ -N p_{i} p_{j} & i \neq j(i, j=1, \ldots, n) 。\end{cases}
$$

A natural interpretation of the Multinomial is possible. Consider the aggregation of the Leontief Inverse $(I-A)^{-1}$, and its intended use for interindustry impact analysis. Assume that the sectors to be subject to exogenous impacts are unknown at the time of aggregation. Further assume that the exogenous impact (the "outcome") is a given dollar amount $N$; in many applications this amount is simply some unit quantity, such as one dollar. If it is deemed equally likely that any one of the original sectors may be exogenously impacted, then an appropriate choice for the $\mathrm{p}$ vector is $p_{i}=1 / n$, all $i$. Alternatively, if it is more likely that the first sector is to be exogenously impacted, then a choice of the $p_{i}$ such that $p_{i}<p_{1}$, all $i=2, \ldots, n$, would be appropriate. 
The first two moments of the Multivariate Normal distribution were directly calibrated. The only requirement was that $\Omega_{g}$ be symmetric and positive definite. In the absence of strong intuition as to likely values for $\Omega_{g}$, a series of pseudo-randomly generated matrices were used. ${ }^{6}$ The only restriction imposed was that the selected values lie within a predetermined range, typically one-fifth of the mean value of the elements of $\mu_{g}$, centered about zero. The results reported below were not qualitatively sensitive to significantly larger values for this range (e.g., ten times the mean value of the $\mu_{g}$ elements).

\subsection{A Venerable Example}

Balderston and Whitin [4] consider the Naive Aggregation of an $18 \times 18$ transactions table for the U.S. in 1939. They examine the effects of three alternative aggregation schemes on the size of particular coefficients of an aggregated $8 \times 8$ Leontief Inverse. ${ }^{7}$ W. D. Fisher [10] subsequently compared these (essentially ad hoc) aggregation schemes with two further schemes chosen to minimize certain "general purpose" criteria of aggregation." He demonstrates that his schemes lead to significantly lower values of his criteria (cf. his Table 4), concluding that "...substantially lower errors may be obtained by deliberate aggregation procedures based on minimal distance ideas than on haphazard procedures" [10, p.259]. Table 4.1 presents several results for this example and the five aggregation schemes just discussed. The first case adopts a Multinomial distribution and the second case adopts a Multivariate distribution, each 
TABLE 4.1: Aggregation Results for Venerable Example

\begin{tabular}{|c|c|c|c|c|}
\hline \multirow[b]{2}{*}{ Case } & \multirow[b]{2}{*}{$\begin{array}{l}\text { Aggregation } \\
\text { Scheme }\end{array}$} & \multicolumn{3}{|c|}{$\begin{array}{c}\text { BAA } R^{2} \\
\text { (Naive } R^{2} \text { ) }\end{array}$} \\
\hline & & $(I-A)$ & $(I-A)^{-1}$ & $\left(I-A^{\prime}\right)^{-1}$ \\
\hline \multirow[t]{5}{*}{1} & BWI & $\begin{array}{l}.99 \\
(.93)\end{array}$ & $\begin{array}{l}.99 \\
(.98)\end{array}$ & $\begin{array}{l}.85 \\
(.60)\end{array}$ \\
\hline & BW2 & $\begin{array}{l}.99 \\
(.97)\end{array}$ & $\begin{array}{l}.99 \\
(.98)\end{array}$ & $\begin{array}{l}.99^{\circ} \\
(.47)\end{array}$ \\
\hline & BW3 & $\begin{array}{l}.99 \\
(.96)\end{array}$ & $\begin{array}{l}.99 \\
(.98)\end{array}$ & $\begin{array}{l}.96 \\
(.70)\end{array}$ \\
\hline & F8 & $\begin{array}{l}.99 \\
(.97)\end{array}$ & $\begin{array}{l}.99 \\
(.98)\end{array}$ & $\begin{array}{l}.98 \\
(.88)\end{array}$ \\
\hline & F13 & $\begin{array}{l}.99 \\
(.98)\end{array}$ & $\begin{array}{l}.99 \\
(.99)\end{array}$ & $\begin{array}{l}.99 \\
(.90)\end{array}$ \\
\hline \multirow[t]{5}{*}{2} & BWI & $\begin{array}{l}.94 \\
(.83)\end{array}$ & $\begin{array}{l}.99 \\
(.97)\end{array}$ & $\begin{array}{l}.90 \\
.61)\end{array}$ \\
\hline & BW2 & $\begin{array}{l}.98 \\
(.92)\end{array}$ & $\begin{array}{r}.99 \\
(.98)\end{array}$ & $\begin{array}{l}.95 \\
(.49)\end{array}$ \\
\hline & BW3 & $\begin{array}{l}.99 \\
(.81)\end{array}$ & $\begin{array}{l}.99 \\
(.85)\end{array}$ & $\begin{array}{l}.96 \\
(.37)\end{array}$ \\
\hline & F8 & $\begin{array}{l}.99 \\
(.91)\end{array}$ & $\begin{array}{l}.99 \\
(.98)\end{array}$ & $\begin{array}{l}.98 \\
(.73)\end{array}$ \\
\hline & F13 & $\begin{array}{l}.99 \\
(.93)\end{array}$ & $\begin{array}{l}.99 \\
(.98) \\
\end{array}$ & $\begin{array}{l}.98 \\
(.77)\end{array}$ \\
\hline
\end{tabular}

\section{Description of Cases:}

(1) Multinomial; $p_{i}=1 / 18=0.0555^{\circ}$, each $i ; N=100$ 。

(2) Maltivariate Normal; each $\mu_{\mathrm{g}}$ element drawn at random from an open interval \pm 0.1 the base period value of the gross output of that sector, each $\Omega_{\mathrm{g}}$ element drawn at random from an open interval \pm 0.01 the base period value of the largest of the two corresponding sectoral gross output; $\Omega_{\mathrm{g}}$ checked for positive definiteness; 1000 random drawings.

Description of Aggregation Schemes:

BW1 : Table II-a, p.119, in Balderston and Whitin [4]。

BW2 : Table III-a, p. 121, in Balderston and Whitin [4].

BW3: Table IV-a, p. 123, in Balderston and Whitin [4].

F8: Aggregation 8, Table 2, p. 275, in W. D. Fisher [10].

F13: Aggregation 13, Table 2, p. 275, in W. D. Fisher [10]. 
of which is described at the bottom of the table. The results for case 2 represent an average over 1000 random drawings.

Several features of the results in Table 4.1 are noteworthy. First, the BAA $\mathrm{R}^{2}$ values are generally very high. Given the limited degree of aggregation undertaken, this result is not too surprising. Second, the BAA $\mathrm{R}^{2}$ exceeds the Naive Aggregate $\mathrm{R}^{2}$ for all cases and aggregation schemes considered.

Third, predictive performance varies with the aggregate model that is under study. In each case shown the BAA for the Leontief Inverse transpose, $\left(I-A^{\prime}\right)^{-1}$, has a lower $R^{2}$ than either of the other two aggregates. Note also that the Naive $\mathrm{R}^{2}$ varies with the matrix in question, although not in the same qualitative way as the BAA variation. ${ }^{9}$ Moreover, the (absolute and relative) deterioration of the Naive $R^{2}$ for the Leontief Inverse transpose is marked.

Fourth, for the distributions considered, virtually all of the three schemes proposed by Balderston and Whitin allow a BAA for (I-A) and $(I-A)^{-1}$ that has just as good an $R^{2}$ as the aggregation schemes preferred by W. D. Fisher。 That is, whatever the "inefficiency" (in terms of Fisher's criteria or the $R^{2}$ measure) associated with Naive aggregation using the $B W$ schemes, there exists a BAA for virtually all of the schemes considered such that the prediction errors from using that aggregate are "close" to zero. In this sense, and for the particular cases studied, the question of the "best" aggregation scheme for prediction purposes has a trivial but practically important answer: choose virtually any scheme. Note that noticeably different 
BAA $R^{2}$ results are obtained for the alternative aggregation schemes when applied to the Leontief Inverse transpose. If schemes were selected on the basis of BAA predictive performance there would be a marginal preference for F13 or BW2 in Case 1 and F8 or F13 in Case 2. However, even for this matrix a BAA is obtained with an $\mathrm{R}^{2}$ of at least 0.85 in Case 1 and 0.90 in Case 2 for any of the aggregation schemes considered.

\subsection{The United States Input-Output Tables}

The U.S. Department of Commerce publicly provides an input-output transactions table for 1975 with 85 sectors in Young and Loftus [44, pp. 69-78]. 10 No official aggregation scheme for this table is endorsed, but one is suggested by the ten boldface groupings in Ritz [33, p. 45]. ${ }^{11}$ We adopt this aggregation scheme from an 85-sector matrix to a 10-sector matrix.

Two exercises were undertaken with the U.S. data, the results of which are reported in Table 4.2. The first exercise involved computing the 10-sector Naive aggregate and using it as the basis for further aggregation to a 3-sector set of matrices; the three sectors were Primary, Secondary and Tertiary. 12 The second exercise dealt with the aggregation from 85 sectors to 10 sectors.

The results support the general conclusions drawn from the example of the previous section. The MSE for the BAA (Naive Aggregate) in Case 1 when $\mathrm{n}=10$ and $\mathrm{m}=3$ are $0.000001(9.86020), 0.00001(1.16784)$ and 0.01672 $(0.04443)$ for the three matrices $(I-A),(I-A)^{-1}$ and $\left(I-A^{\prime}\right)^{-1}$, respectively. The Naive aggregate for the $3 \times 3$ Leontief Inverse in Case 1 is 
TABLE 4.2: Aggregation Results for U.S. Data

\begin{tabular}{|c|c|c|c|c|c|}
\hline \multirow[b]{2}{*}{ Case } & \multirow[b]{2}{*}{$\begin{array}{l}\text { Original } \\
\text { Number of } \\
\text { Sectors (n) }\end{array}$} & \multirow[b]{2}{*}{$\begin{array}{l}\text { Aggregated } \\
\text { Number of } \\
\text { Sectors (m) }\end{array}$} & \multicolumn{3}{|c|}{$\begin{array}{c}\text { BAA } R^{2} \\
\text { (Naive } R^{2} \text { ) }\end{array}$} \\
\hline & & & $(I-A)$ & $(I-A)^{-1}$ & $\left(I-A^{\prime}\right)^{-1}$ \\
\hline 1 & 10 & 3 & $\begin{array}{c}.999 \\
(.995)\end{array}$ & $\begin{array}{l}.999 \\
(.997)\end{array}$ & $\begin{array}{l}.927 \\
(.805)\end{array}$ \\
\hline & 85 & 10 & $\begin{array}{l}.968 \\
(.801)\end{array}$ & $\begin{array}{c}.965 \\
(.812)\end{array}$ & $\begin{array}{l}.974 \\
(.851)\end{array}$ \\
\hline 2 & 10 & 3 & $\begin{array}{c}.993 \\
(.955)\end{array}$ & $\begin{array}{c}.991 \\
(.927)\end{array}$ & $\begin{array}{c}.983 \\
(.906)\end{array}$ \\
\hline & 85 & 10 & $\begin{array}{c}.931 \\
(.744)\end{array}$ & $\begin{array}{c}.944 \\
(.713)\end{array}$ & $\begin{array}{l}.966 \\
(.659)\end{array}$ \\
\hline
\end{tabular}

\section{Description of Cases:}

(1) Multinomial; $p_{i}=1 / n$, each $i ; N=100$ 。

(2) Multivariate Normal; $\mu_{g}$ and $\Omega_{g}$ drawn at random as in Table 4.1; 1000 random drawings for $n=10$ to $m=3$, and 100 random drawings for $\mathrm{n}=85$ to $\mathrm{m}=10$. 


$\left[\begin{array}{rrr}1.32497 & .19794 & .03467 \\ .42548 & 1.76854 & .24929 \\ .24075 & .24215 & 1.21883\end{array}\right]$

whereas the corresponding $\mathrm{BAA}$ is

$$
\left[\begin{array}{rrr}
1.28780 & .15540 & .03960 \\
.40120 & 1.70830 & .28940 \\
.24030 & .24490 & 1.20660
\end{array}\right]
$$

Clearly the two matrices are similar but distinct.

One important feature of the results in $\mathrm{Table} 4.2$ that is novel is the widening differences between the BAA and Naive $R^{2}$ measures as we move from aggregating the 10-sector model to aggregating the 85-sector model. One aspect of this point is the relative stability and high values of the $B A A R^{2}$ over different levels of aggregation and over the aggregation of different matrices.

\subsection{The Australian Input-Output Tables}

The Australian Bureau of Statistics [3] publicly provides an inputoutput transactions table for 1974-75 with 109 sectors. It also provides (Appendix D) an "official" aggregation scheme for a 29-sector table. Table 4.3 presents our results using this aggregation scheme.

The ability of the BAA method to find an aggregate matrix with an $\mathrm{R}^{2}$ of at least 0.9 in each case is again evident. Note also the significant deterioration of the Naive $R^{2}$ relative to the $B A A R^{2}$, especially for the Leontief Inverse transpose relative to the Leontief Inverse. This suggests that the official aggregation scheme implicitly stresses the combination of sectors that are relatively homogeneous in terms of their interindustry output 
TABLE 4.3: Aggregation Results for Australian Data

\begin{tabular}{cccc} 
& \multicolumn{4}{c}{$\begin{array}{c}\text { BAA } R^{2} \\
\left(\text { Naive } R^{2}\right)\end{array}$} \\
\cline { 2 - 4 } 1 & $(I-A)$ & $(I-A)^{-1}$ & $\left(I-A^{\prime}\right)^{-1}$ \\
\hline & $(.91$ & .93 & .91 \\
& .90 & $(.75)$ & $(.58)$ \\
& $(.68)$ & $(.58)$ & $(.92)$ \\
& & & \\
\hline
\end{tabular}

Description of Cases:

(1) Multinomial; $p_{i}=1 / 109=0.0091743$, each $i ; N=100$.

(2) Multivariate Normal; $\mu_{g}$ and $\Omega_{g}$ drawn at random as in Table 4.1; 50 random drawings. 
structure, tending to combine sectors with heterogeneous input (or cost) structures. Of course, this only represents a problem for the eventual application of the aggregate $\left(I-A^{\prime}\right)^{-1}$ matrix if one relies on Naive Aggregation $r$ ather than BAA.

\subsection{A Pacific Basin Input-Output Table}

The Institute of Developing Economies [17, pp. 2-12] provides an international input-output table for 1975 with 8 nations (Indonesia, Malaysia, The Philippines, Singapore, Thailand, Japan, South Korea, and the United States) and with 7 sectors in each nation; thus the entire table distinguishes 56 sectors.

In Table 4.4 we consider the aggregation of the IDE Pacific Basin table over the 8 nations, resulting in a 7-sector table. Clearly the implied aggregation scheme calls for the combination of sectors in the original table that are quite different (e.g., "Agriculture in Thailand" with "Agriculture in the U.S." with "Agriculture in Japan", etc.). Nonetheless, BAA matrices exist that provide predictive $R^{2}$ in excess of 0.90 , while the Naive Aggregate $\mathrm{R}^{2}$ falls as $10 w$ as 0.41 in one case.

\section{CONCLUDING REMARKS}

One important finding from the illustrative applications of the concept of BAA in the previous section is the marked deterioration of predictive power with the various aggregated Leontief Inverse transpose matrices. In these cases the improvement of BAA over Naive Aggregation is clearly significant. This result has some significance for recent applied 
TABIE 4.4: Aggregation Results for Pacific Basin Data

\begin{tabular}{|c|c|c|c|}
\hline \multirow[b]{2}{*}{ Case } & \multicolumn{3}{|c|}{$\begin{array}{c}\text { BAA } R^{2} \\
\text { (Naive } R^{2} \text { ) }\end{array}$} \\
\hline & $(I-A)$ & $(I-A)^{-1}$ & $\left(I-A^{\prime}\right)^{-1}$ \\
\hline 1 & $\begin{array}{c}.91 \\
(.68)\end{array}$ & $\begin{array}{c}.93 \\
(.75)\end{array}$ & $\begin{array}{c}.90 \\
(.61)\end{array}$ \\
\hline 2 & $\begin{array}{c}.90 \\
(.62)\end{array}$ & $\begin{array}{c}.91 \\
(.58)\end{array}$ & $\begin{array}{c}.92 \\
(.41)\end{array}$ \\
\hline
\end{tabular}

Description of Cases

(1) Multinomial; $p_{i}=1 / 56=0.0178571$, each $i ; N=100$ 。

(2) Multivariate Normal; $\mu_{g}$ and $\Omega_{g}$ drawn at random as in Table 4.1; 50 random drawings. 
general equilibrium (GE) modelling efforts, especially in the context of the systematic sensitivity analyses of such models developed in Harrison and Kimbe11 [14]。 One major constraint on these sensitivity analyses is the burden of computing the number of GE solutions required (in the order of $10^{5}$ for models distinguishing about 15 sectors). This computational burden decreases exponentially with the number of sectors identified in the model, providing a strong argument for aggregation. However, there are well-known examples of the loss in predictive power when one aggregates applied GE models (e.g., Fullerton, Henderson and Shoven [11] on the Harberger two-sector aggregation scheme). Given the policy value of examining the robustness of such models, one major application of the BAA method could be to allow a substantial reduction in the dimensionality of the models without substantial loss in predictive power. Preliminary research with the GE model developed in Harrison and Kimbell [13], employing BAA with respect to the input-output data alone (expenditure shares and factor shares were aggregated using Naive methods), suggests that dramatic improvements in predictive power are possible even with severe aggregation (from twenty to two sectors per trading bloc). As expected, GE computational speed is correspondingly improved. Compared to the GE solution using a Naive Aggregate input-output matrix, the improvement in predictive power when using the BAA matrix is dramatic: an $\mathrm{R}^{2}$ with respect to factor usage in each sector of 0.95 as against 0.22 : Interestingly, the $\mathrm{R}^{2}$ difference for other endogenous GE variables is much smaller, although nonetheless significant; welfare impact in each trading bloc has an $R^{2}$ of 0.98 with $\mathrm{BAA}$ as against 0.70 with Naive Aggregation.

University of Western Ontario;

University of Canterbury. 
FOOTNOTES

${ }^{1}$ For helpful discussions and suggestions Claude Autin, David Giles, Mukul Majumdar and Arthur Robson are thanked. Errors remain the authors' responsibility. Harrison thanks the Reserve Bank of Australia and the Social Sciences and Humanities Research Council of Canada for research support.

${ }^{2}$ It has been customary to call this the aggregation bias. However it is more natural to reserve the term "bias" for the expectation of $\left(Y^{*}-\mathrm{Y} \mid \mathrm{X}\right)$; See (2.24) below.

3 David Giles provided a clear derivation of (2.15). He is thanked for this in particular.

${ }^{4}$ Theil [38] proposed a different approach to this problem (one which Allen [1] followed). This was to observe the aggregate variables and fit a relationship between them that explains as much as possible. This involves both a sampling error and the aggregation error discussed in Section 2, of course.. On one interpretation the present approach gives the result of the Theil procedure when all conceivable observations are available.

${ }^{5}$ It is not exactly clear where Fisher made this proposal.

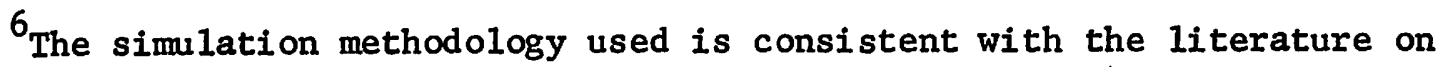
the probabilistic analysis of input-output coefficients: See McCamley, Schreiner and Muncrief [21], Quandt [30,31], and West [41, 42, 43].

7 The transactions table and the three aggregation schemes are published in Balderston and Whitin [4; pp. 116, 119, 121, 123] . 
${ }^{8}$ Specifically, see his aggregations 8 and 13 , defined in his Table 2. Fisher's search over all feasible aggregation schemes for those that minimize his criteria is not exhaustive, but this is of little consequence for present purposes.

${ }^{9}$ Consider, for example, the Leontief Inverse Transpose. In Case 1, changing from BW1 to BW2 leads to a higher BAA $\mathrm{R}^{2}$ but a decline in the Naive $R^{2}$. Similarly for Case 2 .

${ }^{10}$ An Errata to this table has been issued, and was adopted in our data. ${ }^{11}$ Young and Loftus [44, P. 7] repeat the same groupings.

${ }^{12}$ Using the ten sectors listed in Young and Loftus [44, p. 7], "Primary" is an aggregate of "Agriculture, Forestry and Fishing" and "Mining", "Secondary" is an aggregate of "Construction", "Manufacturing" and "Transportation, Communication, and Utilities", and "Tertiary" aggregates the remaining five sectors. 
REFERENCES

[1] Allen, R. G. D.: Mathematical Economics (2nd Edition). London, Macmillan, 1958.

[2] Ara, K.: "The Aggregation Problem in Input-Output Analysis," Econometrica 27 (1959), 257-262.

[3] Australian Bureau of Statistics: Australian National Accounts. InputOutput Tables 1974-75 (Catalogue No. 5209.0). Canberra, Commonwealth Government Printer, 1981.

[4] Balderston, J. B., and Whitin, T. M.: "Aggregation in the Input-Output Mode1," in Oskar Morgenstern (ed.), Economic Activity Analysis. New York: Wiley, 1954.

[5] Chipman, J. S.: "Optimal Aggregation in Large-Scale Econometric Models," Sankhyä 37 (1975), 121-159。

[6] Corden, W. M.: The Theory of Protection. Oxford, Clarendon, 1971.

[7] DeGroot, M. H. : Optimal Statistical Decisions. New York, McGraw-Hill, 1970.

[8] Fei, J. C. H.: "A Fundamental Theorem for the Aggregation Problem of Input-Output Analysis," Econometrica 24 (1956), 400-412.

[9] Fisher, F. M.: "Approximate Aggregation and the Leontief Conditions," Econometrica 37 (1969), 457-469.

[10] Fisher, W. D.: "Criteria for Aggregation In Input-Output Analysis," Review of Economics and Statistics 40 (1958), 250-260.

[11] Fullerton, D., Henderson, Y. K., and Shoven, J. B. : "A Comparis on of Methodologies in Empirical General Equilibrium Models of Taxation," in H. E. Scarf and J. B. Shoven (eds.) Applied General Equilibrium Analysis. New York, Cambridge University Press, 1984. 
[12] Gerking, S. D.: Estimation of Stochastic Input-Output Models : Some Statistical Problems. Leiden, Martinus Nijhoff, 1976.

[13] Harrison, G. W., and Kimbe11, L. J.: "Economic Interdependence in the Pacific Basin: A General Equilibrium Approach," in J. Piggott and J. Whalley (eds.) Policy Use of Numerical Micro-Models: Issues, Applications, and New Developments. London, Cambridge University Press, forthcoming.

[14] Harrison, G. W., and Kimbe11, L. J.: "How Robust Is Numerical General Equilibrium Analysis?" Working Paper No. 8325. Centre for the Study of International Economic Relations, University of Western Ontario, December, 1983.

[15] Hatanaka, M०: "Note on Consolidation Within A Leontief System," Econometrica 20 (1952), 301-303.

[16] Ijiri, Y.: "The Linear Aggregation Coefficient as the Dual of the Linear Correlation Coefficient," Econometrica 36 (1968), 252-259.

[17] Institute of Developing Economies: Internationa1 Input-Output Table for ASEAN Countries: 1975. Tokyo, Asian Economic Press, IDE Statistical Data Series No. 39, 1982.

[18] Kimbe11, L. J. and Harrison, G. W. : "General Equilibrium Analysis of Regional Fiscal Incidence," in H. E. Scarf and J. B. Shoven (eds.), Applied General Equilibrium Analysis. New York, Cambridge University Press, 1984.

[19] Kle1n, L. R.: "Remarks on the Theory of Aggregation," Econometrica 14 (1946), 303-312.

[20] Leontief, W. W.: "Introduction to a Theory of the Internal Structure of Functional Relationships," Econometrica 15 (1947), 361-373. 
[21] McCamley, F., Schreiner, D., and Muncrief, G.: "A Method for Estimating the Sampling Variances of Multipliers Derived from a From-To Mode1," Annals of Regional Science 7 (1973), 81-89.

[22] McManus, M. : "General Consistent Aggregation in Leontief Models," Yorkshire Bulletin of Economic and Social Research 8 (1956), 24-48.

[23] McManus, M.: "On Hatanaka's Note on Consolidation," Econometrica 25 (1956), 282-287.

[24] May, K.: "The Aggregation Problem for a One-Industry Mode1," Econometrica 14 (1946), 285-298.

[25] May, Ko: "Technological Change and Aggregation," Econometrica 15 (1947), 51-63.

[26] Melvin, J. R. : "Short-Run Price Effects of the Corporate Income Tax and Implications for International Trade," American Economic Review 69 (1979), 765-774。

[27] Morimoto, Y०: "On Aggregation Problems in Input-Output Analysis," Review of Economic Studies 37 (1970), 119-126.

[28] Morimoto, $Y_{0}:$ "A Note on Weighted Aggregation in Input-Output Analysis," Internationa1 Economic Review 12 (1971), 138-143.

[29] Neudecker, H.: "Aggregation in Input-Output Analysis : An Extension of Fisher's Method," Econometrica 38 (1970), 921-926.

[30] Quandt, R. E.: "Probabilistic Errors in the Leontief System," Nava1 Research Logistics Quarterly 5 (1958), 155-170.

[31] Quandt, R. E.: "On the Solution of Probabilistic Leontief Systems," Naval Research Logistics Quarterly 6 (1959), 295-305.

[32] Richmond, J.: "Aggregation and Identification," International Economic Review 17 (1976), 47-56. 
[33] Ritz, P. M.: "The Input-Output Structure of the U.S。 Economy, 1972," Survey of Current Business 59 (1979), 34-72.

[34] Roy, J. R., Batten, D. F., and Lesse, P. F.: "Minimizing Information Loss in Simple Aggregation," Environment and Planning A 14 (1982), 973-980.

[35] Scarf, H. E., and Shoven, J. B. (eds.): Applied General Equilibrium Analysis. New York, Cambridge University Press, 1984.

[36] Shoven, J. B., and Whalley, J.: "Applied General Equilibrium Models of Taxation and International Trade," Working Paper No. 8315. Centre for the Study of International Economic Relations, University of Western Ontario, January 1983 (forthcoming, Journal of Economic Literature).

[37] Theil, Ho: Iinear Aggregation of Economic Relations. Amsterdam, North-Holland, 1954.

[38] Theil, H.: "Linear Aggregation in Input-Output Analysis," Econometrica 25 (1957), 111-122.

[39] Thei1, H. : Economics and Information Theory. Ams terdam, North-Holland, 1967.

[40] Theil, H. and Uribe, P.: "The Information Approach to the Aggregation of Input-Output Tables," Review of Economics and Statistics 49 (1967) 451-462.

[41] West, G. Ro: "An Efficient Approach to the Estimation of Regional InputOutput Multipliers," Environment and Planning A 13 (1981), 857-867.

[42] West, G. R०: "Sensitivity and Key Sector Analysis in Input-Output Models," Australian Economic Papers 21 (1982), 365-378。

[43] West, G. R。: Sensitivity and Probabilistic Analysis In Regional InputOutput Models, unpublished $\mathrm{Ph}$.D. Thesis, University of Queensland, Brisbane, Australia, August 1983.

[44] Young, P. C., and Loftus, S. F。: Summary Input-Output Tables of the U.S. Economy: 1973, 1974, and 1975. Washington, D.C., U.S. Department of Commerce, Bureau of Economic Analysis Staff Paper 037, 1981 (plus Eratta). 
$8101 C$

$8102 C$

$8103 C$

$8104 \mathrm{C}$

$8105 C$

$8106 C$

$8107 \mathrm{C}$

8108C D SJ

8109C D SU

$8110 \mathrm{C}$

$8111 \mathrm{C}$

Markusen, James R. Factor Movements and Commodity Trade as Compliments: A Survey of Some Cases.

Conlon, R.M. Comparison of Australian and Canadian Manufacturing Industries: Some Empirical Evidence.

Conlon, R.M. The Incidence of Transport Cost and Tariff Protection: Some Australian Evidence.

Laidler, David. On the Case for Gradualism.

Wirick, Ronald G. Rational Expectations and Rational

Stabilization Policy in an Open Economy

Mansur, Ahsan and John Whalley Numerical \$ecification of Applied

General Equilibrium Models: Estimation, Calibration, and Data.

Burgess, David F., Energy Prices, Capital Formation, and Potential GNP

Jimenez, E. and Douglas $\mathrm{H}$ Keare. Housing Consumption and Income in the Low Income Urban Setting: Estimates from Panel Data in El salvador

Whalley, John Labour Migration and the North-Suth Debate

Manning, Richard and John McMillan Government Expenditure and Comparative Advantage

Freid, Joel and Peter bowitt Why Inflation Reduces Real Interest Rates

$\underline{1982}$

$8201 C$

$8202 C$

$8203 C$

$8204 C$

Manning, Richard and James R. Markusen Dynamic Non- Gubstitution and Long Run Production Possibilities

Feenstra, Robert and Ken Judd Tariffs, Technology Transfer, and Welfare

Ronald $W$. Jones, and Douglas D. Purvis: International Differences in Response to Common External Shocks: The Role of Purchasing Power Parity

James A Brander and Barbara J. Spencer: Industrial strategy with Committed Firms

$8205 C$

Whalley, John, The North-South Debate and the Terms of Trade: An Applied General Equilibrium Approach

$8206 C$

Roger Betancourt, Christopher Clague, Arvind Panagariya CAPI TAL UTI LIZATI ON IN GENERAL EDUILIBRI UM

$8207 \mathrm{C}$

Mansur, Ahsan $H_{6}$ On the Estimation of Import and Export Demand Elasticities and Elasticity Pessimism.

$8208 \mathrm{C}$

Whalley, J. and Randy Wigle PRICE AND QUANTITY RIGIDITIES IN ADJUSTMENT TO TRADE POLICY CHANGES: ALTERNATIVE FORMULATIONS AND INITIAL CALCULATIONS

8209C DSU Jimenez, E. SQUATTING AND COMMUNITY ORGANIZATION IN DEVELOPING COUNTRIES: A CONCEPTUAL FRAMEWORK 
8210C Grossman, G.M. INTERNATIONAL COMPETITION AND THE UNIONIZED SECTOR

8211C Laldler,D. FRIEDMAN AND SCHWARTZ ON MONETARY TRENDS - A REVIEW ARTICLE

8212C Imam, M.H. and Whalley, J. INCIDENCE ANALYSIS OF A SECTOR SPECIFIC MINIMUM WAGE IN A TWO SECTOR HARRIS-TODARO MODEL. 8213C Markusen, J.R. and Melvin, J.R. THE GAINS FROM TRADE THEOREM WITH INCREASING
RETURNS TO SCALE.

8214C INDUSTRIAL ORGANIZATION AND THE GENERAL EQUILIBRIUM COSTS OF PROTECTION IN SMALL OPEN ECONOMIES.

8215C Laidler, D. DID MACROECONOMICS NEED THE RATIONAL EXPECTATIONS REVOLUTION?

8216C Whalley, J. and Wigle, R. ARE DEVELOPED COUNTRY MULTILATERAL TARIFF REDUCTIONS NECESSARILY BENEFICIAL FOR THE U.S.?

8217C Bade, R. and Parkin, M. IS STERLING M3 THE RIGHT AGGREGATE?

8218C Kosch, B. FIXED PRICE EQUILIBRIA IN OPEN ECONOMIES.

$\underline{1983}$

8301C Kimbel1, L.J. and Harrison, G.W. ON THE SOLUTION OF GENERAL EQUILIBRIUM

8302C Melvin, J.R. A GENERAL EQUILIBRIUM ANALYSIS OF'.CANADIAN OIL POLICY.

8303C Markusen, J.R. and Svensson, L.E.0. TRADE IN GOODS AND FACTORS WITH INTERNATIONAL DIFFERENCES IN TECHNOLOGY .

8304C Mohammad, S. Whalley, J. RENT SEEKING IN INDIA: ITS COSTS AND POLICY SIGNIFICANCE.

8305C DSU Jimenez, E. TENURE SECURITY AND URBAN SỌUATTING. 8306C Parkin, M. WHAT CAN MACROECONOMIC THEORY TELL US ABOUT THE WAY DEFICITS
SHOULD BE MEASURED.

8307C Parkin, M. THE INFLATION DEBATE: AN ATTEMPT TO CLEAR THE AIR.

8308C Wooton, I. LABOUR MIGRATION IN A MODEL OF NORTH-SOUTH TRADE. 8309C Deardorff, A.V. THE DIRECTIONS OF DEVELOPING COUNTRIES TRADE: EXAMPLES
FROM PURE THEORY.

8310C Manning, R. ADVANTAGEOUS REALLOCATIONS AND MULTIPLE EQUILIBRIA: RESULTS FOR THE THREE-AGENT TRANSFER PROBLEM. 


\section{$\underline{1983}$}

$8311 \mathrm{C}$ DSU Mohammad, S. and Whalley, J. CONTROLS AND THE INTERSECTORAL TERMS OF TRADE IN INDIA.

8312C Brecher, RIchard A. and Choudhr1, Ehsan U. NEW PRODUCTS AND THE FACTOR CONTENT OF INTERNATIONAL TRADE.

8313C Jones, R.W., Neary, J.P. and Ruane, F.P. TWO-WAY CAPITAL FLOWS: CROSSHAULING IN A MODEL OF FOREIGN INVESTMENT.

8314C DSU Follain, J.R. Jr. and Jimenez, E. THE DEMAND FOR HOUSING CHARACTERISTICS IN DEVELOPING COUNTRIES.

8315C Shoven, J.B. and Whalley, J. APPLIED GENERAL EQUILIBRIUM MODELS OF TAXATION AND INTERNATIONAL TRADE.

8316C Boothe, Paul and Longworth David. SOME IRREGULAR REGULARITIES IN THE CANADIAN/U.S. EXCHANGE MARKET.

$8317 \mathrm{C}$ Hamilton, Bob and Whalley, John. BORDER TAX ADJUSTMENTS AND U.S. TRADE.

8318C Neary, J. Peter, and Schweinberger, Albert G. FACTOR CONTENT FUNCTIONS AND THE THEORY OF INTERNATIONAL TRADE.

8319C Veall, Michael R. THE EXPENDITURE TAX AND PROGRESSIVITY.

8320C Melvin, James R. DOMESTIC EXCHANGE, TRANSPORTATION COSTS AND INTERNATIONAL TRADE.

8321C Hamilton, Bob and Wha1ley, John. GEOGRAPHICALLY DISCRIMINATORY TRADE ARRANGEMENTS .

8322C Bale, Harvey Jr. INVESTMENT FRICTIONS AND OPPORTUNITIES IN BILATERAL U.S.-CANADIAN TRADE RELATIONS.

8323C Wonnacott, R.J. CANADA-U.S. ECONOMIC RELATIONS--A CANADIAN VIEW.

8324C Stern, Robert M. U.S.-CANADIAN TRADE AND INVESTMENT FRICTIONS: THE U.S.: VIEW.

8325C Harrison, Glenn, H. and Kimbe11, Larry, J. HOW ROBUST IS NUMERICAL GENERAL EQUILIBRIUM ANALYSIS?

8326C Wonnacott, R.J. THE TASK FORCE PROPOSAL ON AUTO CONTENT: WOULD THIS SIMPLY EXTEND THE AUTO PACT, OR PUT IT AT SERIOUS RISK?

8327C Bradford, James C. CANADIAN DEFENCE TRADE WITH THE U.S. Conklin, David. SUBSIDY PACTS.

Rugman, Alan M. THE BEHAVIOUR OF U.S. SUBSIDARIES IN CANADA:

IMPLICATIONS FOR TRADE AND INVESTMENTS. 
8328C Boyer, Kenneth D. U.S.-CANADIAN TRANSPORTATION ISSUES.

8329C Bird, Richard M. and Brean, Donald J.S. CANADA-U.S. TAX RELATIONS: ISSUES AND PERSPECTIVES.

8330C Moroz, Andrew R. CANADA-UNITED STATES AUTOMOTIVE TRADE AND TRADE POLICY ISSUES.

8331C Grey, Rodney de C. and Curtis, John. INSTITUTIONAL ARRANGEMENTS FOR U.S.-CANADIAN NEGOTIATIONS. PART I: CANADA-U.S. TRADE AND ECONOMIC ISSUES: DO WE NEED A NEW INSTITUTION? PART II: INSTITUTIONAL ARRANGEMENTS FOR MANAGING THE CANADA-U.S. ECONOMIC RELATIONSHIP.

1984

8401C Harrison, Glenn W. and Manning, Richard. BEST APPROXIMATE AGGREGATION OF INPUT-OUTPUT SYSTEMS. 